\title{
Congenital absence of myocardium of right ventricle: Uhl's anomaly
}

\author{
L. Pérez Díaz, M. Quero Jiménez, F. Moreno Granados, V. Pérez Martínez, and \\ G. Merino Batres \\ From Sección de Cardiología Pediátrica', Clinica Infantil 'La Paz', Madrid, Spain
}

\section{A case of Uhl's anomaly is described. Nine previously published cases are commented upon and the modes of presentation are discussed.}

Uhl's anomaly is an extremely infrequent cardiac malformation, characterized by an almost total absence of the right ventricular myocardium. This results in the inability of the right ventricle to pump blood into the lungs, a function that is carried out by right atrial contraction. The clinical picture is characterized by right heart failure.

The first case was reported by Uhl (1952), in an infant of 7 months, though the Osler's 'parchment heart' could be regarded as an antecedent. Since then, 8 more cases have been reported (Castleman and Towne, 1952; Novak et al., 1957; Taussig, 1960; Arcilla and Gasul, 196I; Reeve and Macdonald, 1964; Cumming, Bowman, and Whytehead, 1965; Perrin and Mehrizi, 1965; Kinare, Panday, and Deshmukh, 1969). One of these, diagnosed by cardiac catheterization and angiocardiography, was still alive at 2 years of age (Arcilla and Gasul, 196r). The remaining cases were erroneously diagnosed in life as Ebstein's anomaly, except for one which was diagnosed as a mediastinal tumour. Necropsy established the correct diagnosis in all of them.

Some cases showed endocardial fibroelastosis of either the right atrium, left atrium, and/or left ventricle. In at least three cases a patent foreman ovale was present.

We report here a further patient with this condition.

\section{Case report}

A male infant was admitted to the Clínica Infantil ' $\mathrm{La}$ Paz' aged 4 months, with signs of congestive heart failure. There was nothing remarkable about his prenatal, birth, and family histories.

Fifteen days before admission, the parents noticed oedema. Dyspnoea and sweating had been present from birth. Several episodes of peripheral cyanosis, cold ex- tremities, and laboured breathing had been observed, without the family doctor having found a satisfactory explanation for it.

Physical examination revealed a well-developed infant in very poor condition with generalized oedema. Cyanosis while crying was intense. Peripheral pulses were regular but feeble in both brachial and femoral arteries. The liver edge was $5 \mathrm{~cm}$ below the right costal margin. No praecordial impulse was noted. The heart sounds were muffled in intensity and there were no murmurs. After digitalis a third heart sound was heard. Lung auscultation was normal. Chest $x$-ray showed conspicuous cardiac enlargement and reduced pulmonary vascular markings (Fig. I).

The electrocardiogram (Fig. 2) revealed peaked and tall $\mathbf{P}$ waves, indicating right atrial hypertrophy. Praecordial tracings showed 'qr' complexes of a very low voltage from $V_{3} R$ to $V_{3}$ leads, and ' $r s$ ' complexes in the remaining leads. Nonspecific ST-T wave changes were present.

The infant was admitted to the hospital with the presumptive diagnosis of myocardiopathy, pericarditis, Ebstein's anomaly, or Uhl's anomaly. In spite of treatment with digitalis, diuretics, and oxygen, his condition deteriorated rapidly and he died some hours later.

At necropsy the heart appeared large, filling almost all of the left hemithorax and as a result the left lung was small and compressed. Approximately 5 to $10 \mathrm{ml}$ crystalline, clear fluid was removed from the pericardial sac.

External examination of the heart showed a normal relation between the great arteries, and normal systemic and pulmonary venous returns. The right atrium and the right ventricle were considerably dilated, the latter having a whitish, nearly transparent and easily depressible wall (Fig. 3). The left atrium and left ventricle appeared normal.

Internal examination showed a dilated and hypertrophied right atrium. The foramen ovale was sealed. The tricuspid valve was attached normally to its annulus. The right ventricle was extremely dilated, but its wall was unusually thin, being less than I $\mathrm{mm}$ thick, with an 


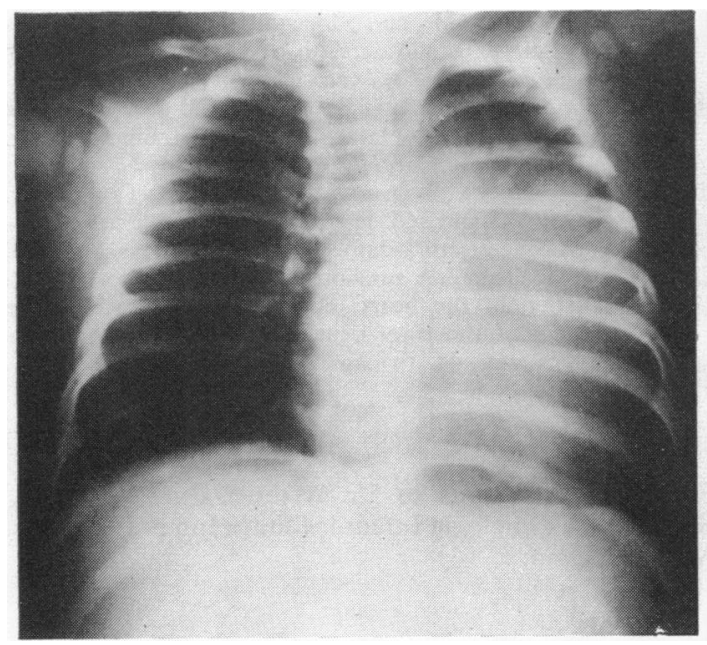

FIG. I Posteroanterior chest x-ray. Severe cardiac enlargement and reduced pulmonary vascular markings.

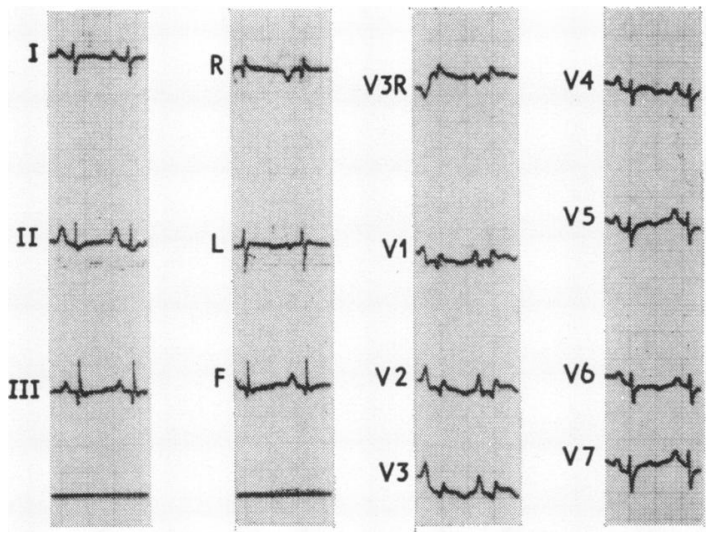

FIG. 2 The electrocardiogram reveals right atrial hypertrophy, low voltage, and ' $q r$ ' complexes from $V_{3} R$ to $V_{3}$ leads.

almost total absence of muscle fibres between the endocardial and epicardial layers, except in some sparse areas adjacent to the basal region. The crista supraventricularis was hypoplastic, the outflow tract and the pulmonary artery being normal. The left atrium and left ventricle were normal and no signs of endocardial fibroelastosis were found. The origin and distribution of coronary vessels were normal.

\section{Discussion}

The differential diagnosis of this malformation includes mainly such entities as Ebstein's anomaly, pericardial effusion, primary myocardial fibro-

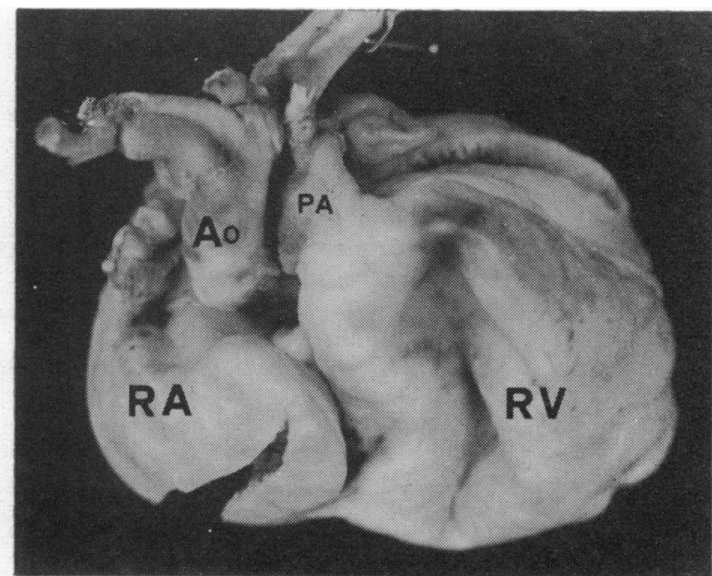

FIG. 3 External frontal view of the heart showing a thin and easily depressible right ventricular wall. The right atrium $(R A)$ and right ventricle $(R V)$ are dilated. $P A$, pulmonary artery; Ao, aorta.

elastosis, glycogen storage disease of the heart, anomalous origin of the left coronary artery from the pulmonary artery, etc., and has been fully described by others (Gasul, Arcilla, and Lev, 1966). Isolated hypoplasia of the right ventricle should also be considered in the differential diagnosis (Pérez, Quero, and Moreno, 1971 ; Hollman, 1968).

Gasul et al. (1966), using haemodynamic studies, showed that it was the right atrium which pumped blood to the right ventricle and pulmonary vascular bed, the right ventricle being merely a passive channel. Anatomical findings in our case (thickened right atrial wall with absent muscular fibres of the right ventricle) seem to agree with the haemodynamic features described by them.

In our patient, the right atrium apparently performed its pumping function adequately until is days before death, when right heart failure became obvious. We think it is important to consider the bouts of peripheral cyanosis, cold extremities, and respiratory difficulties. In our opinion, they could be due to the right atrial failure, triggered by transient episodes of increased pulmonary vascular resistance or increased body requirements, with a low cardiac output.

We think these episodes of low cardiac output can be added to the description of Uhl's anomaly.

\section{References}

Arcilla, R. A., and Gasul, B. M. (196I). Congenital aplasia or marked hypoplasia of the myocardium of the right ventricle (Uhl's anomaly). Fournal of Pediatrics, 58, 381 . 
Castleman, B., and Towne, V. W. (1952). (Editors.) Case records of Massachusetts General Hospital. New England Fournal of Medicine, 246, 785 .

Cumming, G. R., Bowman, J. M., and Whytehead, L. (1965). Congenital aplasia of the myocardium of the right ventricle (Uhl's anomaly). American Heart fournal, 70, 671 .

Gasul, B. M., Arcilla, R. A., and Lev, M. (1966). Heart Disease in Children. Pitman Medical Publishing Co., London.

Hollman, A. (1968). Underdevelopment of the right ventricle. In Pediatric Cardiology, p. 50r. Ed. by Hamish Watson. Lloyd-Luke, London.

Kinare, S. G., Panday, S. R., and Deshmukh, S. M. (1969). Congenital aplasia of the right ventricular myocardium (Uhl's anomaly). Diseases of the Chest, 55, 429.

Novak, G., Szanto, P. B., Gasul, B. M., and Dillon, E. (1957). Congenital aplasia of the myocardium of the right ventricle. Proceedings of the Institute of Medicine of Chicago, 21, 334.

Perrin, E. V., and Mehrizi, A. (1965). Isolated free-wall hypoplasia of the right ventricle. American fournal of Diseases of Children, 109, 558.
Pérez, V. M., Quero, M., and Moreno, F. (I97I). Hipoplasia primitiva del ventrículo derecho. Archivos del Instituto de Cardiologia de México, 41, 568.

Reeve, R., and Macdonald, D. (1964). Partial absence of the right ventricular musculature: partial parchment heart. American fournal of Cardiology, 14, 415.

Taussig, H. B. (1960). Congenital Malformations of the Heart, 2nd ed., pp. 138 and 466. Harvard University Press, Cambridge, Massachusetts; Oxford University Press, London.

Uhl, H. S. M. (1952). A previously undescribed congenital malformation of the heart: almost total absence of the myocardium of the right ventricle. Bulletin of the fohns Hopkins Hospital, 91, 197.

Requests for reprints to Dr. Manuel Quero Jiménez, Sección de Cardiología Infantil, Clínica Infantil 'La Paz', Madrid, Spain. 